SUMMARY

Obesity is a risk factor for many diseases. Thirty per cent of Americans are viewed as super obese; therefore, we need to find a solution. We already know about the diseases associated with obesity such as high blood pressure, diabetes, sleep apnoea, etc. Lately, there has been an increased interest in understanding if cancer is related to obesity. In this paper, we review the incidence of colon cancer and obesity.

Insulin is the best established biochemical mediator between obesity and colon cancer. Hyperinsulinaemia, such as occurs in type II diabetes, is important in the pathogenesis of colon cancer. All adipose tissue is not equal. Visceral abdominal fat has been identified as the essential fat depot for pathogenetic theories that relate obesity and colon cancer. The genders differ as regards to how the relationship between obesity and colon cancer has been evaluated. Obesity imposes a greater risk of colon cancer for men of all ages and for premenopausal women than it does for postmenopausal women. Regular exercise reduces the risk of developing colon cancer and the risk of death from colon cancer should it develop. We believe that a combination of waist circumference (WC) and body mass index (BMI) measurements is recommended to assess the obesity related risk of developing colon cancer. Radiographic assessments of visceral abdominal fat may eventually prove to be the best means of assessing a patient's obesity related risk of developing colon cancer.

Although WC is better established as a measure of obesity than BMI, the evidence for colon cancer risk is not secure on this point; combining BMI and WC measurements would appear, at present, to be the wisest approach for colon cancer risk assessment. Doctors who wish to decrease their patients' risk of dying of colon cancer should advise weight loss and exercise. Conversely, physicians and public health authorities should consider both exercise and obesity when designing colon cancer screening protocols. Morphometric cut offs should be adjusted, if possible, for age, sex, ethnicity, and height.

\title{
INTRODUCTION
}

Colon cancer is the second most common cause of cancer death. ${ }^{1}$ The rapid increase in colon cancer incidence in several populations previously considered to be at low risk for this disease, ${ }^{2}$ the 20 -fold difference in incidence between high incidence and low incidence regions, ${ }^{3}$ and the incidence changes observed in migrant studies ${ }^{45}$ suggest environmental factors, including diet, ${ }^{6-9}$ as aetiological agents. This review concerns studies that relate obesity to colon cancer. As will be shown, insulin resistance and type II diabetes loom large in the theoretical framework that connects obesity and colon cancer. In this review diabetes always refers to type II diabetes and, unless otherwise indicated, colon cancer refers to colorectal adenocarcinoma.

\section{INSULIN AND LEPTIN}

Obesity ${ }^{10-13}$ and physical inactivity ${ }^{14}{ }^{15}$ are strong independent determinants of insulin resistance and hyperinsulinaemia. A diet high in refined sugars and low in fibre, often linked to colon cancer, ${ }^{16}$ also causes hyperinsulinaemia. ${ }^{17}$ Increased blood insulin levels lower insulin-like growth factor binding protein 1 levels, and often later lead to increased free insulin-like growth factor 1 (IGF-1) levels. ${ }^{18}$ IGF-1 is associated both with percentage of body fat and WC, a reason why WC may ultimately prove to be a better risk assessment measurement than BMI. ${ }^{19}$ IGF-l acts as a procarcinogen, both by decreasing cell death and encouraging cell growth. ${ }^{20}{ }^{21}$ IGF- 1 is known to be involved with the development, progression, and metastatic potential of colon cancer. ${ }^{22}$ Insulin itself stimulates the growth of colon cancer cell lines. ${ }^{23-25}$

Serum C peptide levels are a surrogate test for insulin secretion. Kaaks and colleagues ${ }^{26}$ compared 102 women with colon cancer with 200 controls, and found that patients with the highest levels of $\mathrm{C}$ peptide had almost three times the risk of colon cancer compared with patients 
with the lowest levels of $\mathrm{C}$ peptide. Ma and colleagues ${ }^{27}$ compared 176 men with colon cancer with 294 matched controls and found that patients with the highest levels of $\mathrm{C}$ peptide had over three times the risk of colon cancer over patients with the lowest levels of C peptide. In contrast, Wie and colleagues $^{28}$ compared 195 women with colon cancer with 350 matched controls and failed to find a difference in C peptide levels. Of the recent studies that evaluated IGF- 1 and colon cancer risk, none show statistically significant results when a Bonferroni adjustment was applied..$^{26-30}$ In summary, experimental studies link IGF-1 to colon cancer; epidemiological studies show hyperinsulinaemia imparts an increased risk of colon cancer. The best epidemiological evidence for an association between obesity, colon cancer, and diabetes may well be that noted by Giovannuci ${ }^{31}$ who found a striking correlation between colon cancer and type 2 diabetes geographic patterns and changes with relation to time and economic development.

Obesity increases serum leptin levels. ${ }^{32}$ Leptin may also be responsible for colon cancer but the evidence is less clearcut. ${ }^{33}$ Leptin was shown to increase the growth and proliferation of a colon cancer cell line, as evidence by BrdU incorporation and c-fos expression. ${ }^{34}$ Leptin was shown to work as a mitogen for intestinal epithelial cells and also decreased apoptotic cell death in a cancer cell line. ${ }^{35}$ Leptin has also been shown to induce invasion of collagen gel by cell lines derived from colonic adenomas ${ }^{36}$ and to enhance the development of adenomatous lesions in genetically predisposed mice. ${ }^{37}$ In contrast, a study showed that leptin did not increase cell proliferation in vivo in mice. ${ }^{38}$ A second study showed that in vivo leptin did not promote the growth of colon cancer xenografts in mice. ${ }^{39}$ A third study found that leptin actually reduced the incidence of drug induced adenomas in rats. ${ }^{40}$ In one study, men, but not women, with the highest blood levels of leptin had over twice the colon cancer risk of those with the lowest levels. ${ }^{41}$ Thus epidemiology associates elevated leptin levels with colon cancer in men, but the mechanism for this association has not been fully demonstrated. The relationship between insulin resistance,

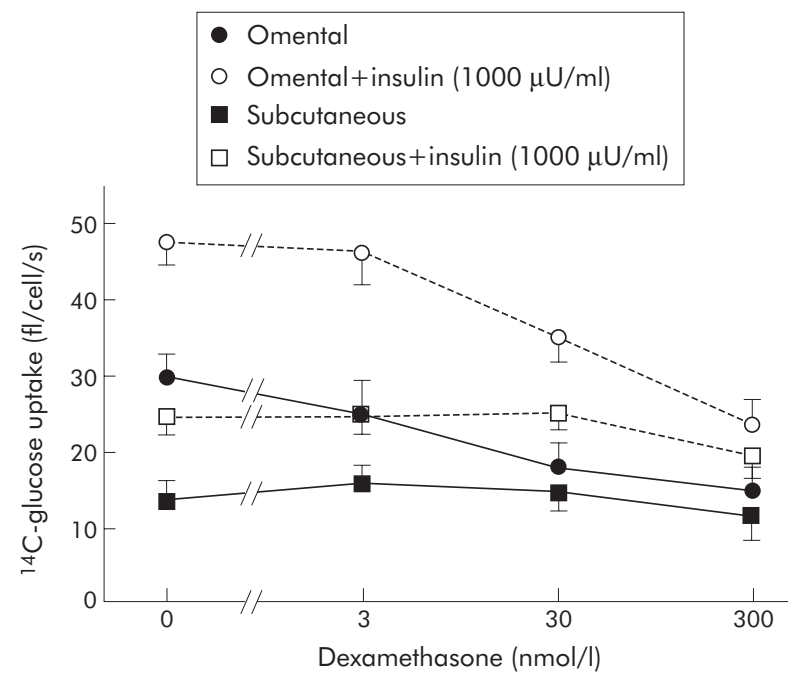

Figure 1 Effects of dexamethasone administration on glucose uptake of omental and subcutaneous fat cells, with and without insulin (from Lundgren and colleagues ${ }^{44}$ ). obesity, and colon cancer is emphasised because insulin is the better established biochemical mediator.

\section{VISCERAL ABDOMINAL FAT (VAF)}

The above summary should not be allowed to obscure the complexity of the relationship between adipose tissue and insulin; the adipocyte has a multifaceted relationship with insulin that involves the sympathetic and parasympathetic nervous systems. In fact, as best described by Giorgino and colleagues, ${ }^{42}$ there are distinct differences in subcutaneous fat and VAF in their functions as regards insulin. Experimentally, mice predisposed to develop visceral abdominal obesity developed hyperinsulinaemia and preneoplastic colonic mucosal changes more often than mice without visceral abdominal obesity. ${ }^{43}$ Lundgren and colleagues ${ }^{44}$ evaluated samples of omental and subcutaneous fat taken from 18 non-diabetic patients and evaluated the influence of insulin and steroid administration on glucose uptake of these cells. Figure 1, taken from the article, ${ }^{44}$ displays the results; note (1) glucose uptake in general, (2) insulin induced glucose uptake, and (3) steroid blockade of this insulin induced uptake are all greater in omental than in subcutaneous adipocytes.

VAF has been specifically correlated with changes that relate to diabetes in patients. Salmenniemi and colleagues ${ }^{45}$ evaluated 129 non-diabetic Finnish offspring, of diabetic parents, whose average BMI was $26.2 \mathrm{~kg} / \mathrm{m}^{2}$, and found intra-abdominal fat mass, but not total fat mass, correlated with increased plasma insulin levels. Park and Lee $^{46}$ evaluated 88 obese Koreans who underwent a three month weight reduction programme and found that, after taking into account age, sex, and BMI, changes in VAF, but not subcutaneous fat, correlated with changes in serum triglycerides. Klein and colleagues ${ }^{47}$ evaluated 15 women who had undergone extensive subcutaneous liposuction procedures; there were no changes in insulin sensitivity of the liver, skeletal muscle, or adipose tissue, no changes in inflammatory mediators, and no changes in plasma glucose, insulin, or lipid concentrations. Hence, as best summarised by Freedland, ${ }^{48}$ one may posit a relationship between VAF and insulin sensitivity: weight gain increases VAF past a threshold into which the patient passes into the phase of insulin resistance. Figure 2, from Freedland's article, ${ }^{48}$ illustrates this quite nicely; the theory may not fully correspond to reality.

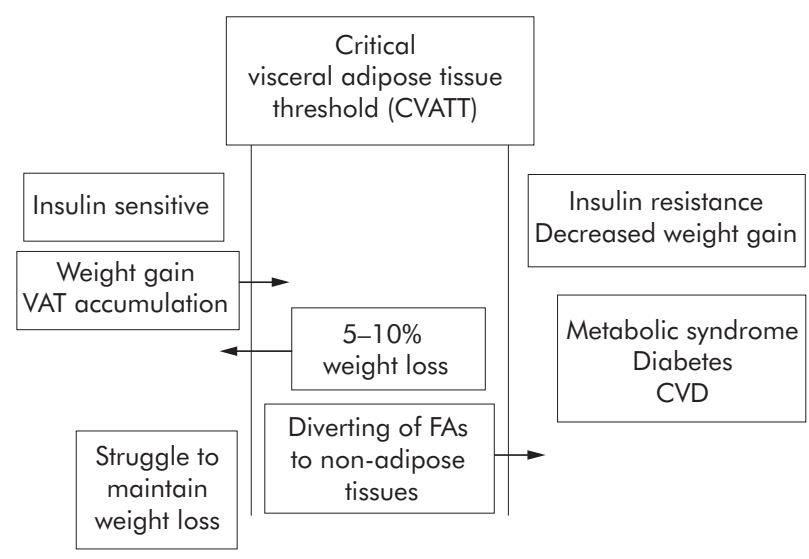

Figure 2 Theoretical framework that includes weight gain, visceral adipose tissue, and insulin resistance (from Freedland ${ }^{48}$ ). VAF, visceral abdominal fat; FAs, fatty acids; CVD, cardiovascular disease. 
Although VAF and insulin levels are related, the relationship is complex and has not been fully elucidated. Hanley and colleagues $^{49}$ evaluated 95 native Canadians and found that a baseline WC measurement correlated with a change in proinsulin levels; given that six separate multivariate analyses were performed, the results cannot be said to be statistically significant at $\mathrm{p}=0.01$. Tong and colleagues ${ }^{50}$ prospectively evaluated 518 non-diabetic JapaneseAmerican men and women and found that baseline fasting insulin levels, C peptide levels, and leptin levels all correlated with VAF area five and 10 years later; the results were statistically significant, independent of subcutaneous fat accumulation. The action of VAF may itself depend on whether or not the patient has diabetes; Anjana and colleagues $^{51}$ studied 82 non-diabetic and 82 diabetic Asian Indians and found that, whereas for non-diabetic subjects VAF measured by computerised tomography (CT) correlated with haemoglobin $\mathrm{A}_{\mathrm{lc}}$ levels $(r=0.424, \mathrm{p}<0.0001)$, this was not true for diabetics $(r=-0.017, \mathrm{p}>0.05)$. Hence, as emphasised by Frayn, ${ }^{52}$ the relationship of fat and insulin may be more correlative than causative. From a risk assessment standpoint, those with an easily ascertained increased risk of colon cancer deserve more active screening, irrespective of causation. More importantly, specific identification of VAF as a critical correlate infers a theoretical advantage to using WC over BMI for risk assessment because the former better correlates with VAF. ${ }^{53}{ }^{54}$ That women tend to accumulate VAF less with weight gain than men $^{55}$ is one explanation for the gender differences in the relationship between the risk of colon cancer and obesity; this explanation is complicated by comparisons of postmenopausal and premenopausal women, as detailed in the next section.

\section{SEX AND THE MENOPAUSE}

Odds ratios and relative risks approximate one another ${ }^{56}$; some general comments about differences between the sexes can be made by evaluating aggregate studies that compare men and women. Figure 3 displays the relative risks/odds ratios of colon cancer for the most overweight category for 10 $\operatorname{articles}^{57-66}$ that compared men and women; a sign test showed that these studies found that obesity placed men more than women at an increased risk for colon cancer $(\mathrm{p}<0.025)$. Only one study, of Japanese subjects, ${ }^{59}$ showed

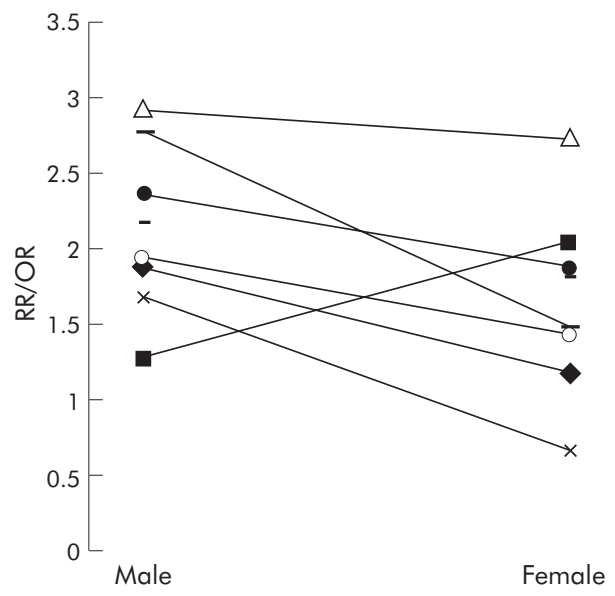

Figure 3 Results of 10 studies $^{57-66}$ that compared the relative risk/odd ratios (RR/OR) of colon cancer of the most obese men and women with normal weight men and women.
Table 1 Results of multiple linear regression of the natural logarithm of relative risks/odds ratios of seven studies $^{57} 646668-71$ on body mass index (BMI) group, female sex, and the interaction of BMl group and female sex

\begin{tabular}{lclll}
\hline Variable & Coefficient & $\begin{array}{l}\text { Standard } \\
\text { error }\end{array}$ & $\boldsymbol{T}$ & $\mathbf{p ~ V a l u e ~}$ \\
\hline Intercept & -0.26 & & & \\
BMl group & 0.19 & 0.028 & 6.67 & $5.47 \times 10^{-8}$ \\
Female sex & 0.38 & 0.14 & 2.61 & 0.0097 \\
BMl group $\times$ female sex & -0.129 & 0.04 & 3.38 & 0.002 \\
\hline
\end{tabular}

$r^{2}=0.57 ; F=0.57$; regression degrees of freedom $=3$; residual degrees of freedom $=40 ; p=2.08 \times 10^{-7}$

The regression equation for men is:

In(relative risk/odds ratio) $=-0.26+0.19 \times \mathrm{BMl}$ group

The regression equation for women is:

In(relative risk/odds ratio) $=0.12+0.06 \times \mathrm{BMl}$ group .

women to be more at risk than men; the impact of ethnicity will be discussed in the last section of this review.

Seven articles $^{64}{ }^{6-71}$ divided each of six sets of women and five sets of men into five BMI groups. The lowest group in each group was eliminated because its relative risk/odds ratio is always 1. Each of the six sets of women and five sets of men bears four BMI group specific, gender specific relative risks/odds ratios: there are 44 data points. Relative risks and odds ratios are calculated by taking their logarithms. The natural logarithm of relative risk/odds ratio is the dependent ( or Y) variable. BMI group, female sex, and female sex $\times$ BMI group are independent (or $\mathrm{X}$ ) variables. Multiple linear regression results are shown in table 1 ; variability of the three independent variables accounted for $57 \%$ of the variability in relative risk/odds ratios $(\mathrm{p}<0.0001)$. Each independent variable was statistically significant. No outliers were present; neither was there heterscedasticity or curvilinearity. Although a positive coefficient for female sex appears to imply that women have, in general, a greater relative risk of colon cancer, this is not true because the interaction variable (female sex $\times$ BMI group) shows that there are two regression equations. That there are two regression equations implies that the sexes differ as regards the relationship between obesity and colon cancer.

The effect of obesity is more pronounced for men than women. Although for BMI group 2 the estimated relative risk/odds ratio was just slightly greater for women than for men, men had an increasingly greater relative risk/odds ratio than women for BMI groups 3, 4, and 5. As a person gains weight, there is a much more modest rise in colon cancer risk for women than there is for men.

If VAF is indeed an important factor, the difference between the sexes may exist because BMI is a better measure of VAF in men than in women. ${ }^{64} 7273$ On the other hand, given the lack of an epidemiological connection between leptin and colon cancer in women, there may be real biological differences at work. Differences between men and women often relate to oestrogen; the two matters best explored in this regard are menopausal status and the use of oestrogenic hormones in postmenopausal women.

Conversion of androgens to oestrogens by adipose tissue is the prime source of extraglandular oestrogen in postmenopausal women; age and obesity increase circulating oestrogen levels. ${ }^{74-76}$ Oestrogen supplementation in men, but not women, increases insulin resistance; the higher the oestradiol/testosterone ratio, the greater are plasma glucose and 
Table 2 Results of the study of Slattery and colleagues ${ }^{57}$ and Lin and colleagues ${ }^{71}$ evaluating the interaction of body mass index (BMI) and hormone replacement therapy (HRT) among postmenopausal women with regard to the risk of colon cancer

\begin{tabular}{|c|c|c|c|c|c|}
\hline & \multicolumn{5}{|c|}{ BMI $\left(\mathrm{kg} / \mathrm{m}^{2}\right)$} \\
\hline & $\overline{<23}$ & $23-24.9$ & $25-26.9$ & $27-29.9$ & $\geqslant 30$ \\
\hline \multicolumn{6}{|c|}{ Relative risk-Slattery and colleagues ${ }^{57}$} \\
\hline \multirow{4}{*}{$\begin{array}{l}\text { HRT not used } \\
\text { HRT used }\end{array}$} & 1.00 & 1.95 & 1.36 & 1.06 & 3.06 \\
\hline & 1.00 & 0.79 & 1.02 & 1.84 & 1.25 \\
\hline & \multicolumn{5}{|c|}{ BMI $\left(\mathrm{kg} / \mathrm{m}^{2}\right)$} \\
\hline & $<23$ & $23-24$ & $25-27$ & $28-30$ & $>30$ \\
\hline \multicolumn{6}{|c|}{ Odds ratio- - Lin and colleagues ${ }^{71}$} \\
\hline HRT not used & 1.00 & 1.09 & 1.19 & 1.06 & \\
\hline HRT used & 1.00 & 2.69 & 1.68 & 2.28 & 3.36 \\
\hline
\end{tabular}

insulin levels. ${ }^{77} 78$ If hyperinsulinaemia increases the risk of colon cancer, obesity induced hyperoestrogenaemia in men would be one reason why obesity in men causes an increased colon cancer risk; this theory is unsupported by epidemiology.

If hyperoestrogenaemia from obesity causes a greater colon cancer risk in men than in women, one might conclude that: (1) premenopausal women would be less affected by obesity than postmenopausal women because premenopausal women have ovarian oestrogen that might make any added oestrogen from obesity less important ${ }^{79}$; and (2) hormone replacement therapy (HRT) in postmenopausal women would increase the risk of death from colon cancer. The two best studies that have assessed menopausal status and colon cancer risk have shown that conclusion (1) is false: Slattery and colleagues ${ }^{57}$ found that postmenopausal women who have a BMI $>30 \mathrm{~kg} / \mathrm{m}^{2}$ have 1.29 times the risk of women with a BMI $<23 \mathrm{~kg} / \mathrm{m}^{2}$ and, for premenopausal women, a ratio of 2.19; Terry and colleagues ${ }^{80}$ found that postmenopausal women who have a BMI $>30 \mathrm{~kg} / \mathrm{m}^{2}$ have 0.92 times the risk of women with a BMI $<25$ and, for premenopausal women, a ratio of 1.75. These findings are perplexing given that the menopause is associated with a redistribution of fat towards the abdomen. ${ }^{55} 81$

The latter conclusion is well supported by studies of age. In Sweden, obese women younger than 55 years, but not older, had a twofold increased colon cancer risk..$^{82}$ Obesity conferred a twofold colon cancer risk for nurses aged 34-39 years ${ }^{33}$ but not for a group of women mostly over 65 years. ${ }^{83}$ The issue is not simple; Dutch women with an age at menarche above 13 years had an odds ratio of 0.51 (95\% confidence interval 0.28-0.94) of those who had their first periods below age 14 years. ${ }^{84}$ In general, however, the consensus is that obesity may confer just as great an added colon cancer risk for women who are premenopausal as it does for men in general..$^{85} 86$

As with most matters that concern HRT, the risks of colon cancer are best described as undecided. Although Calle and colleagues ${ }^{87}$ found that HRT reduced the risk of colon cancer, only seven of 14 studies cited in her table 6 bear an overall risk of 0.9 or less among those who received HRT. The confusion is perhaps better illustrated by the results of two studies on this issue displayed in table 2: the results of Slattery and colleagues ${ }^{57}$ lead one to believe that obesity and HFT together increase colon cancer risk; those of Lin and colleagues $^{71}$ lead to the opposite conclusion.

\section{PHYSICAL ACTIVITY}

Given that exercise is a time honoured technique for weight loss, it is of interest to ascertain its relationship to colon cancer. Many studies have been performed concerning this issue. Samad and colleagues ${ }^{88}$ conducted a meta-analysis of the association between physical activity and reduced risk of colorectal cancer. The results combine odds ratios and relative risks; because results are pooled and not isolated for each study, separate analyses for case control and cohort studies were performed. Results for case control studies are provided in table 3. Note that for men and for women, the risk relationships of exercise and colorectal cancer are similar; note also that the risk reduction only occurs with respect to non-rectal colon cancer.

A sedentary lifestyle may partly account for the higher rates of colon cancer in industrialised countries and urban areas. ${ }^{89}$ Studies of exercise have one common flaw: BMI and WC are precisely measured ${ }^{90}$ and the degree of physical activity is not. ${ }^{91}{ }^{92}$ Moreover, one theoretical cause of the decrease in colon cancer risk by physical activity, an increase in colonic motility, is not firmly established. ${ }^{16}$ Not even the relationship between physical activity and colonic motility is straightforward: among those with low physical activity levels, physical activity stimulates colonic motility; for others the relation is unclear. ${ }^{93-95}$ None the less, the risk reduction from exercise is reasonably well established; Slattery estimates that $12-14 \%$ of colon cancers can be attributed to lack of frequent involvement in vigorous exercise. ${ }^{96}$

A recent article showed that patients who develop colon cancer do better if they are physically active and slender before they received their diagnosis. ${ }^{97}$ The study, which took into account age, sex, and tumour stage, found that the physically inactive faced 1.3 times the hazard of death as the physically active; this was especially true among patients with stage II-III cancers where the physically inactive were

Table 3 Pooled estimates of Samad and colleagues ${ }^{88}$ for case control studies assessing the effect of exercise on the risk of colon cancer for men and women

\begin{tabular}{llll}
\hline Sex & Location & OR/RR & $95 \% \mathrm{Cl}$ \\
\hline Male & Non-Rectal & 0.684 & $0.572-0.818$ \\
& Rectum & 0.946 & $0.832-1.076$ \\
Female & Non-Rectal & 0.621 & $0.407-0.761$ \\
& Rectum & 0.870 & $0.514-1.474$ \\
\hline
\end{tabular}

$\mathrm{OR} / \mathrm{RR}$, odds ratio/relative risk; $95 \% \mathrm{Cl}, 95 \%$ confidence interval. 
almost twice as likely to die. Each added $10 \mathrm{~cm}$ of WC increased the hazard of dying by 1.25. The bottom line is conventional wisdom: to increase one's life expectancy one should exercise frequently.

\section{MEASURES OF OBESITY}

A recent study showed that direct radiographic evaluation of VAF area may be the best predictor for colon cancer. ${ }^{98} \mathrm{CT}$ assessed VAF area for two groups of patients, 51 with and 52 without colorectal adenomas. Although there was no real difference in BMI between the groups, patients with adenomas had, on average, 1.5 times the VAF area of patients without adenomas $(\mathrm{p}<0.001)$. Increased VAF area was also associated with an increased number of adenomas, larger size of the largest adenoma, and more aggressive histology (tubulovillous/villous versus tubular). In the cardiovascular area, radiographically assessed VAF area has also shown its worth; Miyawaki and colleagues ${ }^{53}$ evaluated $^{2}$ 955 normal weight Japanese subjects and found that VAF area was better than BMI in discriminating patients with risk factors for atherosclerosis. Expensive radiographic studies such as CT will, for the foreseeable future, be of little use as risk assessment tools, but ultrasonographic measurements, which may find their way into the clinician's office, are beginning to be explored. ${ }^{55}$

The great debate for the present is whether or not WC is a better risk assessment measure than BMI. On a general basis, WC is preferred. Wang and Hoy ${ }^{99}$ evaluated 915 Aboriginal Australians, 143 of whom had diabetes, and found by receiver operating characteristic curve analysis that WC was better than BMI in discriminating non-diabetic from diabetic patients. Zoico and colleagues ${ }^{100}$ studied 68 Italians aged $66-$ 77 years and found variations in WC accounted for more variation in insulin resistance than leptin or adiponectin; moreover, sex, age, and total body fat did not yield information of significance. The importance of WC, especially as it better relates to VAF than $\mathrm{BMI}^{, 3}$ has led to WC being preferred to BMI as a diagnostic criterion for metabolic syndrome. $^{54}$

The debate is not settled as regards colon cancer risk. Caan and colleagues ${ }^{64}$ compared 1983 patients who developed colon cancer with 2400 age and sex matched population controls. Height, weight, WC, and hip circumferences were obtained by trained interviewers. BMI and waist/hip ratio were calculated. Elevated BMI was the only independent risk factor for both men and women.

The Framingham study ${ }^{101}$ measured BMI and WC of 3764 subjects aged 30-54 years and 3802 aged 55-79 years old. Those 30-54 years old with a BMI of $30 \mathrm{~kg} / \mathrm{m}^{2}$ had 1.5 times the risk of those with a lower BMI; for subjects 55-79 years old, the relative risk was 2.4. The effect of an increased BMI was more pronounced for men than women; it was also more pronounced for proximal than for distal colon cancers. Patients with a large WC (over $99.0 \mathrm{~cm}$ or more for women and $101.5 \mathrm{~cm}$ for men) had twice the colon cancer risk of those with a smaller WC. Further analysis showed the risk bore a linear relationship to WC, that this was true for both proximal and distal colon cancers, and that the relative risk of a large waist did not decrease when BMI was taken into account. The results of this study favoured WC over BMI.

The conventional WC limits for obesity related disease ( $102 \mathrm{~cm}$ for men and $88 \mathrm{~cm}$ for women) are well known to be in need of further adjustment. ${ }^{102}$ Ethnicity plays a vital role in establishing cut offs for WC; Lear and colleagues ${ }^{103}$ studied
Table 4 Waist circumference limits, above which a higher risk of future coronary events (based on 10 year risk of coronary events or the presence of diabetes) exists, stratified by body mass index (BMI) group and sex (from Ardeen and colleagues ${ }^{106}$ )

\begin{tabular}{lllll}
\hline & BMI $\left(\mathrm{kg} / \mathrm{m}^{2}\right)$ & & \\
\cline { 2 - 5 } & $18.5-24.9$ & $25-29.9$ & $30-34.9$ & $\geqslant 35$ \\
\hline Men & $\geqslant 90 \mathrm{~cm}$ & $\geqslant 100 \mathrm{~cm}$ & $\geqslant 110 \mathrm{~cm}$ & $\geqslant 125 \mathrm{~cm}$ \\
Women & $\geqslant 80 \mathrm{~cm}$ & $\geqslant 90 \mathrm{~cm}$ & $\geqslant 105 \mathrm{~cm}$ & $\geqslant 115 \mathrm{~cm}$ \\
\hline
\end{tabular}

92 Chinese and 99 European men and women and found that while WC did correlate with metabolic risk factors for men and women (Chinese and European) there was an interaction with WC and ethnicity such that cut offs for Europeans could not be applied to Chinese patients. Despite these caveats, results of WC samplings in children of differing ethnic groups are frightening because significant numbers exceeded the adult cut off value for obesity related diseases as early as age 13 years. ${ }^{104}$ One intriguing finding is that although the BMI was devised to take height into account, it underestimates obesity risks in short persons ${ }^{105}$; it hardly needs stating that basketball players and jockeys might need different WC cut offs.

At present, it might be wisest to use both BMI and WC for colon cancer risk assessment purposes. Attempts are now underway ${ }^{106}$ to create WC thresholds within BMI categories and to specify limits for age and ethnicity. Table 4 displays proposed WC limits within BMI categories that would place a patient at risk of future coronary events.

\section{CONCLUSION}

Insulin is the best established biochemical link between obesity and colon cancer; controlling hyperinsulinaemic states, such as the metabolic syndrome and diabetes, may be a means of reducing a person's risk of colon cancer. Leptin may also be responsible for the increased risk of colon cancer that obesity confers but it is not on as firm a ground experimentally as insulin. VAF, not subcutaneous or total body fat, is established as the particular location for which the presumptive metabolic risk factors for colon cancer lie; obesity related colon cancer risk assessments should, theoretically, concentrate on this area. Men of all ages and premenopausal women, more than postmenopausal women, are at increased risk for colon cancer if they are obese; intensive colon cancer screening of obese men and premenopausal women is better justified than increased screening of obese postmenopausal women. Vigorous exercise reduces the risk of obesity related colon cancer; it should be recommended for all obese persons as a means of reducing both the risk of developing colon cancer and the risk of dying from colon cancer should it develop. Although WC is better established as a measure of obesity than BMI, the evidence for colon cancer risk is not secure on this point; combining BMI and WC measurements would appear, at present, to be the wisest approach for colon cancer risk assessment. Doctors who wish to decrease their patient's risk of dying of colon cancer should advise weight loss and exercise. Conversely, physicians and public health authorities should consider both exercise and obesity when designing colon cancer screening protocols. Morphometric cut offs should be adjusted, if possible, for age, sex, ethnicity, and height. 
a...................

\section{Authors' affiliations}

E E Frezza, M S Wachtel, M Chiriva-Internati, Texas Tech University Health Sciences Center, Texas, USA

Conflict of interest: None declared.

\section{REFERENCES}

1 Parkin D. Estimates of the worldwide incidence of 25 major cancers in 1990 Int J Cancer 1999:80:827-41.

2 Willett W. The search for the causes of breast and colon cancer. Nature 1989;338:389-94.

3 Tomatis L, editor. Cancer: causes, occurrence and control, IARC Sci Publ No 100. Lyon: International Agency for Research on Cancer, 1990.

4 Haenszel W, Kurihara M. Studies of Japanese migrants. I. Mortality from cancer and other diseases among Japanese in the United States. J Natl Cancer Inst 1968;40:43-68.

5 Whittemore AS, Zheng S, Wu A, et al. Colorectal cancer in Chinese and Chinese-Americans. Natl Cancer Inst Monogr 1985;69:43-6.

6 Doll R, Peto R. The causes of cancer: quantitative estimates of avoidable risks of cancer in the United States today. J Natl Cancer Inst 1981;66:1 191-308.

7 Nelson N. Is chemoprevention overrated or under-funded? J Natl Cancer Inst 1996;88:947-9

8 Steinmetz KA, Potter JD. Vegetables, fruit, and cancer. II. Mechanisms. Cancer Causes Control 1991;2:427-42.

9 Slavin JL, Martini MC, Jacobs DR Jr, et al. Plausible mechanisms for the protectiveness of whole grains. Am J Clin Nutr 1999:70(suppl):459-63.

10 Biorntorp P. Metabolic implications of body fat distribution. Diabetes Care $1991 ; 14: 1132-43$

11 Kissebah AH, Vydelingum N, Murray R, et al. Relation of body fat distribution to metabolic complications of obesity. J Clin Endocrinol Metab 1982:54:254-60.

12 Krotkiewski M, Biorntorp P, Sjostrom L, et al. Impact of obesity on metabolism in men and women. Importance of regional adipose tissue distribution. J Clin Invest 1983;72:1150-62.

13 Donahue RP, Abbott RD, Bloom E, et al. Central obesity and coronary heart disease in men. Lancet 1987;1:821-4.

14 Koivisto VA, Yki-Jarvinen H, DeFronzo RA. Physical training and insulin sensitivity. Diabetes Metab Rev 1988;1:445-81.

15 Regensteiner JG, Mayer EJ, Shetterly SM, et al. Relationship between habitual physical activity and insulin levels among nondiabetic men and women. San Luis Valley Diabetes Study. Diabetes Care 1991:14:1066-74.

16 Potter JD, Slattery ML, Bostick RM, et al. Colon cancer: a review of the epidemiology. Epidemiol Rev 1993;15:499-545.

17 Riccardi G, Rivellese AA. Effects of dietary fiber and carbohydrate on glucose and lipoprotein metabolism in diabetic patients. Diabetes Care 1991;14:1115-25.

18 Powell DR, Suwanichkul A, Cubbage ML, et al. Insulin inhibits transcription of the human gene for insulin-like growth factor-binding protein-1. J Biol Chem 1991; 266:18868-76.

19 Kojantie E, Fall CHD, Seppala $M$, et al. Serum insulin-like growth factor (IGF)-I and IFG-binding protein-1 in elderly people: relationships with cardiovascular risk factors, body composition, size at birth, and childhood growth. J Clin Endocrinol Metab 2003;88:1059-65.

20 LeRoith D, Baserga R, Helman L, et al. Insulin-like growth factors and cancer Ann Intern Med 1994; 122:54-9.

21 Baserga R, Hongo A, Rubini $M$, et al. The IGF-1 receptor in cell growth, transformation and apoptosis. Biochim Biophys Acta 1997;1332:F105-26.

22 Singh P, Rubin R. Insulin-like growth factors and binding proteins in colon cancer. Gastroenterology 1993;105:1218-37.

23 Watkins LF, Lewis LR, Levine AE. Characterization of the synergistic effects of insulin and transferrin and the regulation of their receptors on a human colon carcinoma cell line. Int J Cancer 1990;45:372-5.

24 Koenuma M, Yamori T, Tsuruo T. Insulin and insulin-like growth factor 1 stimulate proliferation of metastatic variants of colon carcinoma 26. Jpn J Cancer Res 1989;80:51-8.

25 Biork J, Nilsson J, Hultcrantz R, et al. Growth-regulatory effects of sensory neuropeptides, epidermal growth factor, insulin, and somatostatin on the non-transformed intestinal epithelial cell line IEC-6 and the colon cancer cell line HT 29. Scand J Gastroenterol 1993;28:879-84.

26 Kaaks R, Toniolo P, Akhmedkhanov A, et al. Serum c-peptide, insulin-like growth factor (IGF)-1, IGF binding proteins, and colorectal cancer risk in women. J Natl Cancer Inst 2000;92:1592-600.

27 Ma J, Giovannucci E, Pollak M, et al. A prospective study of plasma cpeptide and colorectal cancer risk in men. J Natl Cancer Inst 2004;96:546-553.

28 Wie EK, Ma J, Pollak MN, et al. A prospective study of c-peptide, insulin like growth factor-1, insulin-like growth factor binding protein-1 and the risk of colorectal cancer in women. Cancer Epidemiol Biomarkers Prev 2005; 14:850-5

29 Palmqvist R, Hallmans G, Rinaldi S, et al. Plasma insulin-like growth factor 1 , insulin-like growth factor binding protein 3 , and risk of colorectal cancer: a prospective study in northern Sweden. Gut 2002;50:642-6.

30 Giovannucci E, Pollak MN, Platz EA, et al. A prospective study of plasma insulin-like growth factor-1 and binding protein-3 and risk of colorecta neoplasia in women. Cancer Epidemiol Biomarkers Prev 2000;9:345-9.

31 Giovannuci E. Insulin, insulin-like growth factors and colon cancer: a review of the evidence. J Nutr 2001;131:3109-20S.

32 Bruce WR, Giacca A, Medline A. Possible mechanisms relating diet and risk of colon cancer. Cancer Epidemiol Biomarkers Prev 2000;9:1271-9.
33 Sierra-Honigmann MR, Nath AK, Murakami C, et al. Biological action of leptin as an angiogenic factor. Science 1998;281:1683-6.

34 Liu Z, Uesaka T, Watnanabe H, et al. High fat diet enhances colonic cell proliferation and carcinogenesis in rats by elevating serum leptin. Int $J$ Oncol 2001; 19:1009-14.

35 Rouet-Benzineb P, Aparicio T, Guilmeau S, et al. Leptin counteracts sodium butyrate-induced apoptosis in human colon cancer HT-29 cells via NF-kB signaling. J Biol Chem 2004;279:16495-502.

36 Attoub S, Veerle N, Pirola L, et al. Leptin promotes invasiveness of kidney and colonic epithelial cells via phosphoinositide 3-kinase-, Rho-, and Racdependent signaling pathways. Faseb J 2000;14:2329-38

37 Hirose Y, Hata K, Kuno T, et al. Enhancement of development of azoxymethane-induced colonic premalignant lesions in $\mathrm{C} 57 \mathrm{BL} / \mathrm{Ks} \mathrm{J}-\mathrm{db} / \mathrm{db}$ mice. Carcinogenesis 2004;25:821-5.

38 FitzGerald AJ, Mandir N, Goodlad RA. Leptin, cell proliferation and crypt fusion in the gastrointestinal tract of intravenously fed rats. Cell Prolif 2005;38:25-33.

39 Aparicio T, Kotelevets L, Tsocas A, et al. Leptin stimulates the proliferation of human colon cancer cells in vitro but does not promote the growth of colon cancer xenografts in nude mice nor intestinal tumourigenesis in APcMin/+ Mice. Gut 2005;54:1136-45.

40 Aparico T, Giulmeau S, Goiot H. Leptin reduces the development of initial precancerous lesions induced by azoxymethane in the rat colonic mucosa. Gastroenterology 2004;126:499-510.

41 Stattin P, Palmqvist R, Soderberg S, et al. Plasma leptin and colorectal cance risk: a prospective study in northern Sweden. Oncol Rep 2003;10:2015-21.

42 Giorgino F, Laviola L, Eriksson JW. Regional differences of insulin action in adipose tissue: insights from in vivo and in vitro studies. Acta Physiol Scand 2005; 183:13-30

43 Cowey SL, Quast M, Belalcazar LM, et al. Abdominal obesity, insulin resistance and colon carcinogenesis are increased in mutant mice lacking gastrin gene expression. Cancer 2005; 103:2643-53.

44 Lundgren $M$, Buren J, Ruge T, et al. Glucocorticoids down-regulate glucose uptake capacity and insulin signaling proteins in omental but not subcutaneous human adipocytes. J Clin Endocrinol Metab 2004;89:2989-97.

45 Salmenniemi U, Ruotsalainen E, Vanttinen M, et al. High amount of viscera fat mass is associated with multiple metabolic changes in offspring of type 2 diabetic patients. Int J Obesity 2005;29:1464-70.

46 Park HS, Lee K. Greater beneficial effects of visceral fat reduction compared with subcutaneous fat reduction on parameters of the metabolic syndrome: study of weight reduction programmes in subjects with visceral and subcutaneous obesity. Diabet Med 2005;22:266-72

47 Klein S, Fontana L, Young VL, et al. Absence of an effect of liposuction on insulin action and risk factors for coronary heart disease. N Engl J Med 2004;350:2549-57.

48 Freedland ES. Role of a critical visceral adipose tissue threshold (CVATT) in metabolic syndrome: implications for controlling dietary carbohydrates: a review. Nutr Metab 2004;1:12.

49 Hanley AJG, McKeown-Eyssen G, Harris SB, et al. Cross-sectional and prospective associations between abdominal adiposity and proinsulin concentration. J Clin Endocrinol Metab 2002;87:77-83.

50 Tong J, Fujimoto WY, Kahn SE, et al. Insulin, C-peptide, and leptin concentrations predict increased visceral adiposity at 5- and 10-year followups in nondiabetic Japanese Americans. Diabetes 2005;54:985-90.

51 Anjana M, Sandeep S, Deepa R, et al. Visceral and central abdominal fat and anthropometry in relation to diabetes in Asian Indians. Diabetes Care 2004; $27: 3948-53$

52 Frayn KN. Obesity and metabolic disease: is adipose tissue the culprit? Proc Nutr Sci 2005;64:7-13.

53 Miyawaki T, Abe M, Yahata K, et al. Contribution of visceral fat accumulation to the risk factors for atherosclerosis in non-obese Japanese. Int Med 2004;43:1138-44.

54 Carr DB, Utzschneider KM, Hull RL, et al. Intra-abdominal fat is a major determinant of the national cholesterol education program adult treatment panel III criteria for the metabolic syndrome. Diabetes 2004;53:2087-94.

55 Waichenberg BL. Subcutaneous and visceral adipose tissue: their relation to the metabolic syndrome. Endocr Rev 2000;21:697-738.

56 Fleiss JL. Some properties of the odds ratio and its logarithm. Statistical methods for rates and proportions. 2nd Edn New York: John Wiley and Sons, 1981:64-7.

57 Slattery ML, Ballard-Barbash R, Edwards S, et al. Body mass index and colon cancer: an evaluation of the modifying effects of estrogen (United States) Cancer Causes Control 2003;14:75-84.

58 Murphy TK, Calle EE, Rodriquez C, et al. Body mass index and colon cance mortality in a large prospective study. Am J Epidemiol 2000;152:847-54.

59 Kuriyama S, Tsubono Y, Hozawa A, et al. Obesity and risk of cancer in Japan. Int J Cancer 2005;113:148-57.

60 Ford ES. Body mass index and colon cancer in a national sample of adult US men and women. Am J Epidemiol 1999;150:390-8.

61 Kune GA, Kune S, Watson LF. Body weight and physical activity as predictors of colorectal cncer risk. Nutr Cancer 1990;13:9-17.

62 Wu AH, Paganini-Hill A, Ross RK, et al. Alcohol, physical activity and other risk factors for colorectal cancer: a prospective study. $\mathrm{Br} J$ Cancer 1987;55:687-94

63 Slattery ML, Potter J, Caan BJ, et al. Energy balance and colon cancerbeyond physical activity. Cancer Res 1997;57:75-80.

64 Caan BJ, Coats AO, Slattery ML, et al. Body size and the risk of colon cance in a large case-control study. Int J Obesity 1998;22:178-84.

65 Graham S, Marshall J, Haughey B, et al. Dietary epidemiology of cancer of the colon in Western New York. Am J Epidemiol 1988;128:490-503. 
66 Gerhardsson de Verdier M, Hagman U, Steineck G, et al. Diet, body mass and colorectal cancer: a case-referent study in Stockholm. Int J Cancer 1990;46:832-8.

67 Cossrow N, Falkner B. Race/ethnic issues in obesity and obesity-related comorbitidies. J Clin Endocrinol Metabol 2004;89:2590-4,

68 Martienez ME, Giovannucci E, Spiegelman D, et al. Leisure-time activity, body size, and colon cancer in women. J Natl Cancer Inst 1997;89:948-55.

69 Slattery ML, Potter J, Caan B, et al. Energy balance and colon cancerbeyond physical activity. Cancer Res 1997;57:75-80.

70 Lee IM, Paffenbarger RS Jr. Quetelet's index and risk of colon cancer in college alumni. J Natl Cancer Inst 1992;84:1326-31.

71 Lin J, Zhang SM, Cook NR, et al. Body mass index and risk of colorectal cancer in women (United States). Cancer Causes Control 2004;15:581-9.

72 Le Marchand L, Wilkens LR, Mi MP. Obesity in youth and middle age and risk of colorectal cancer in men. Cancer Causes Control 1992:3:349-54.

73 Martinez ME, Giovannucci E, Spiegelman D, et al. Leisure-time physical activity, body size, and colon cancer in women. Nurses' Health Study Research Group. J Natl Cancer Inst 1997:89:948-55.

74 Simpson ER, Bulun SE, Nichols JE, et al. Estrogen biosynthesis in adipose tissue: regulation by paracrine and autocrine mechanisms. J Endocrinol 1996; 150(suppl):S51-7

75 Gordon GG, Olivo J, Rafil F, et al. Conversion of androgens to estrogens in cirrhosis of the liver. J Clin Endocrinol Metab 1975;40:1018-26.

76 Edman CD, MacDonald PC. Effect of obesity on conversion of plasma androstenedione to estrone in ovulatory and anovulator young women. Am J Obstet Gynecol 1978;130:456-61.

77 Polderman KH, Gooren $\sqcup$, Asscheman $\mathrm{H}$, et al. Induction of insulin resistance by androgens and estrogens. J Clin Endocrinol Metab 1994;79:265-71.

78 Tchernof A, Despres JP, Dupont A, et al. Relation of steroid hormones to glucose tolerance and plasma insulin levels in men. Importance of visceral adipose tissue. Diabetes Care 1995; 18:292-9.

79 Bernstein L, Ross RK. Endogenous hormones and breast cancer risk. Epidemiol Rev 1993;15:48-65.

80 Terry PD, Miller AB, Rohan TE. Obesity and colorectal cancer risk in women Gut 2002;51:191-4.

81 Kolasa KM. Weight and abdominal-fat distribution in menopausal women. Clin Fam Pract 2002;4:41-52.

82 Terry P, Giovannucci E, Bergkvist L, et al. Body weight and colorectal cancer risk in a cohort of Swedish women: relation varies by age and cancer site. Br J Cancer 2001:85:346-9.

83 Martinez M, Giovannucci E, Spiegelman D, et al. Leisure-time physical activity, body size, and colon cancer in women. J Natl Cancer Inst 1997;89:948-55

84 van Wayenburg CAM, van der Schouw YT, van Noord PAH, et al. Age at menopause, body mass index, and the risk of mortality in the Dutch Diagnostisch Onderzoek Mammacarcinoom (DOM) Cohort. Epidemiology 2000;11:304-8.

85 Shike M. Body weight and colon cancer. Am J Clin Nutr 1996;63/suppl 3):442-4.

86 World Cancer Research Fund. Food, nutrition and the prevention of cancer: a global perspective. Washington DC: World Cancer Research Fund/American Institute for Cancer Research, 1997.
87 Calle EE, Miracle-McMahill HL, Thun MJ, et al. Estrogen replacement therapy and risk of fatal colon cancer in a prospective cohort of postmenopausal women. J Natl Cancer Inst 1995;87:517-23.

88 Samad AKA, Taylor RS, Marshall T, et al. A meta-analysis of the association of physical activity with reduced risk of colorectal cancer. Colorectal Dis 2005;7:204-13.

89 Boyle P, Zaridze DG, Smans M. Descriptive epidemiology of colorectal cancer. Int J Cancer 1985;36:9-18.

90 Rimm EB, Stampfer MJ, Colditz GA, et al. Validity of self-reported waist and hip circumferences in men and women. Epidemiology 1990;1:466-73

91 Siconolfi SF, Lasater TM, Snow RC, et al. Self-reported physical activity compared with maximal oxygen uptake. Am J Epidemiol 1985;122:101-5.

92 Albanes D, Conway JM, Taylor PR, et al. Validation and comparison of eight physical activity questionnaires. Epidemiology 1990;1:65-71.

93 Bingham SA, Cummings $\mathrm{JH}$. Effect of exercise and physical fitness on large intestinal function. Gastroenterology 1989;97:1389-99.

94 Oettle GJ. Effect of moderate exercise on bowel habit. Gut 1991;32:941-4.

95 Coenen C, Wegener M, Wedmann B, et al. Does physical exercise influence bowel transit time in healthy young men? Am J Gastroenterol 1992;87:292-5

96 Slattery ML. Physical activity and colorectal cancer. Sports Med 2004;34:239-52.

97 Haydon AMM, Maclnnis RJ, English DR, et al. Effect of physical activity and body size on survival after diagnosis with colorectal cancer. Gut 2006;55:62-7.

98 Otake S, Takeda, H, Suzuki Y, et al. Association of visceral fat accumulation and plasma adiponectin with colorectal adenoma: evidence for participation of insulin resistance. Clin Cancer Res 2005;11:3642-6.

99 Wang Z, Hoy WE. Body size measurements as predictors of type 2 diabetes in Aboriginal people. Int J Obesity 2004;28:1580-4.

100 Zoico E, Di Francesco V, Mazzali G, et al. Adipocytokines, fat distribution, and insulin resistance in elderly men and women. $J$ Gerontol 2004;59A:935-9.

101 Moore LL, Bradlee ML, Singer MR, et al. BMI and waist circumference as predictors of lifetime colon cancer risk in Framingham Study adults. Int J Obes Relat Metab Disord 2004;28:559-67.

102 Lemieux S, Paquette MC. Body weight classification. Can Med Ass J 2005; 172:1275-6

103 Lear SA, Chen MM, Frohlich JJ, et al. The relationship between waist circumference and metabolic risk factors: cohorts of European and Chinese descent. Metabolism 2002;51:1427-32.

104 Fernandez JR, Redden DR, Pietrobelli A, et al. Waist circumference percentiles in nationally representative samples of African-American, European-American, and Mexican-American children and adolescents. J Pediatr 2004; 145:439-44.

105 dos Santos DM, Sichieri R. Body mass index and measures of adiposity among elderly adults. Rev Saude Publica 2005;39:163-8.

106 Ardeen $\mathrm{Cl}$, Janssen I, Ross $\mathrm{R}$, et al. Development of health-related waist circumference thresholds within BMl categories. Obes Res 2004; 12:1094-103. 